\title{
Tissue RNFT2 Expression Levels Are Associated With Peritoneal Recurrence and Poor Prognosis in Gastric Cancer
}

\author{
MASAHIRO SASAHARA, MITSURO KANDA, DAI SHIMIZU, CHIE TANAKA, YOSHIKUNI INOKAWA, \\ NORIFUMI HATTORI, MASAMICHI HAYASHI, GORO NAKAYAMA and YASUHIRO KODERA \\ Department of Gastroenterological Surgery (Surgery II), \\ Nagoya University Graduate School of Medicine, Nagoya, Japan
}

\begin{abstract}
Background/Aim: Disease recurrence is frequently observed after curative resection of advanced gastric cancer resulting in a poor prognosis. In the present study, we identified a candidate biomarker to predict recurrence and prognosis after curative resection of gastric cancer. Materials and Methods: A transcriptome analysis was conducted using surgically resected cancerous tissue from patients with metastatic gastric cancer to identify genes that are upregulated in primary and metastatic tissues. Results: Ring finger protein, transmembrane 2 (RNFT2) mRNA expression was upregulated in primary gastric cancer tissues and metastases compared with non-cancerous tissues. RNFT2 expression in gastric cancer cell lines was positively correlated with the EMT-related molecules GSC, MMP9, and RAC1. The RNFT2 high expression group exhibited a significantly shorter postoperative overall survival. Peritoneal recurrence was significantly higher in the RNFT2 high expression group. Conclusion: RNFT2 mRNA expression predicts peritoneal recurrence and is a potential prognostic biomarker for gastric cancer following curative gastrectomy.
\end{abstract}

Gastric cancer has become the leading cause of cancerrelated deaths worldwide (1). Despite advances in our understanding of the pathogenesis and treatment of gastric cancer, the recurrence rate after radical gastrectomy remains high and prognosis is poor $(2,3)$. The identification of biomarkers that predict gastric cancer metastasis and recurrence will enable physicians to predict the risk of

This article is freely accessible online.

Correspondence to: Mitsuro Kanda, MD, Ph.D., Department of Gastroenterological Surgery (Surgery II), Nagoya University Graduate School of Medicine, 65 Tsurumai-cho, Showa-ku, Nagoya 466-8550, Japan. Tel: +81 527442249, Fax: +81 527442255, e-mail: m-kanda@med.nagoya-u.ac.jp

Key Words: Gastric cancer, RNFT2, prognosis, peritoneal recurrence. recurrence in individual patients $(4,5)$. Perioperative chemotherapy and postoperative follow-up, considering the respective risks, may contribute to the prevention of recurrence, early detection, and improved prognosis.

The type of recurrence and metastasis of gastric cancer include lymph node recurrence, hematogenous metastasis and peritoneal dissemination. Among them, in particular peritoneal metastasis is difficult to detect early and systemic chemotherapy is largely ineffective. As a result, peritoneal metastasis is a major cause of poor prognosis in gastric cancer (6).

Defining the risk of peritoneal metastasis is necessary for prediction and early detection, but there are currently no established biomarkers.

To identify differentially expressed genes that associate with the metastasis of gastric cancer, we conducted a transcriptome analysis of gastric clinical specimens from patients with distant metastasis. We identified a ring finger protein, transmembrane 2 (RNFT2), as a novel candidate biomarker. RNFT2 has been implicated in mediating protein interactions and the ubiquitination of target proteins, but its role in gastric cancer has not been reported. In the present study, we investigated the relationship between RNFT2 mRNA expression in gastric cancer tissues and the likelihood of recurrence after curative gastrectomy.

\section{Materials and Methods}

Ethics. This study conformed to the ethical guidelines of the World Medical Association Declaration of Helsinki Ethical Principles for Medical Research Involving Human Subjects and was approved by the Institutional Review Board of Nagoya University, Japan (Approval Number 2014-0043). Written informed consent for the use of clinical samples and data was obtained from all patients.

Transcriptome analysis. Surgically resected gastric and metastatic tissues from four patients with hepatic metastasis were subjected to transcriptome analysis. Global expression profiling was conducted using the Illumina HiSeq platform (San Diego, CA, USA) to evaluate the expression of 57,749 genes in primary gastric cancer tissues compared with corresponding noncancerous adjacent gastric mucosa. Cell lines. Fourteen gastric cancer cell lines (AGS, GCIY, IM95, 


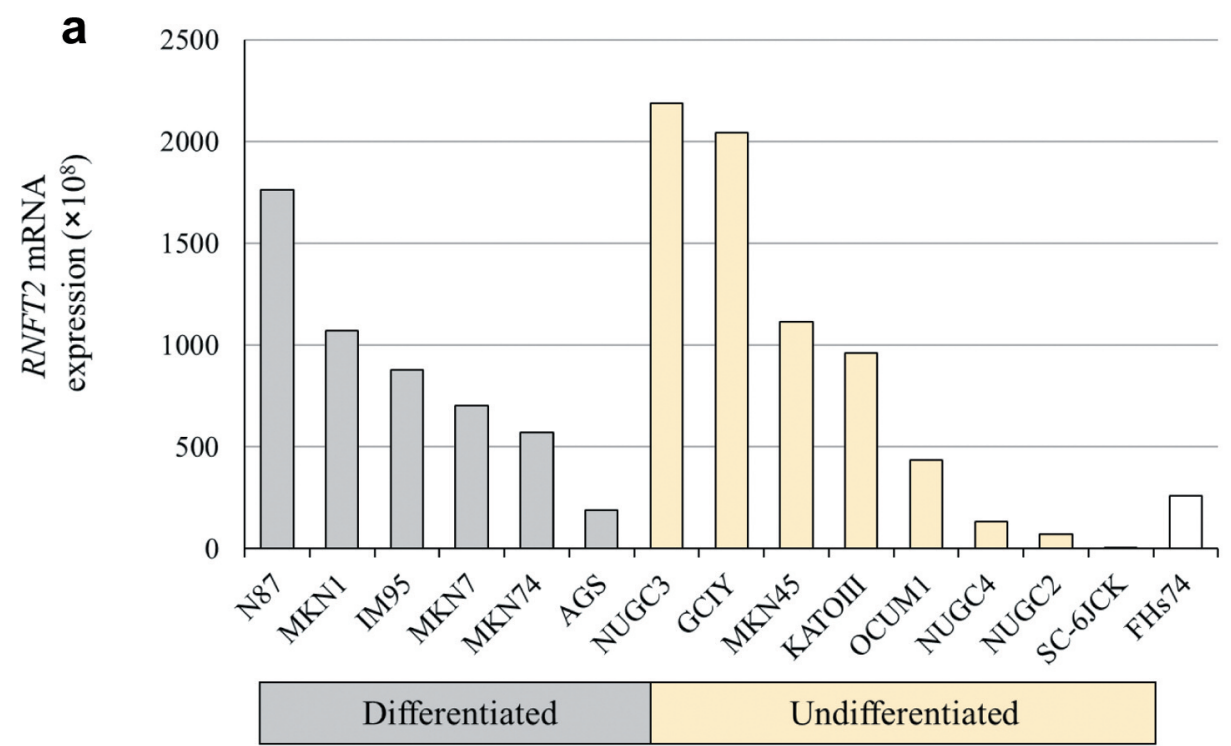

b

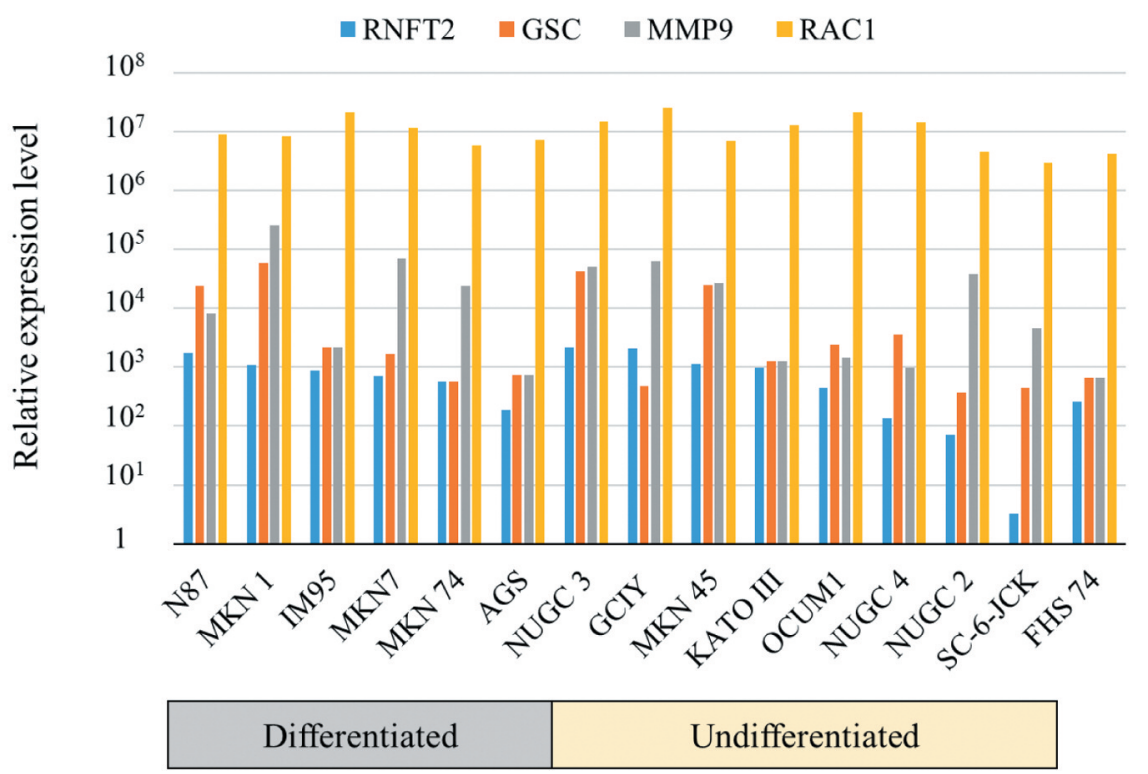

Figure 1. Continued

KATOIII, MKN1, MKN7, MKN45, MKN74, N87, NUGC2, NUGC3, NUGC4, OCUM1, and SC-6-JCK) and a non-tumorigenic epithelial cell line (FHs74) were obtained from the American Type Culture Collection (ATCC; Manassas, VA, USA) or the Japanese Collection of Research Bioresources Cell Bank (JCRB; Osaka, Japan). The cell lines were cultured in RPMI-1640 (Sigma- Aldrich, St. Louis, MO, USA) supplemented with $10 \%$ fetal bovine serum at $37^{\circ} \mathrm{C}$ in an atmosphere containing $5 \% \mathrm{CO}_{2}$.

Quantitative real-time reverse-transcription polymerase chain reaction $(q R T-P C R)$ and PCR array analysis. Total RNA (10 $\mu \mathrm{g}$ per sample) was isolated from cells and tissues and used to generate complementary DNA (cDNA) and amplified using gene-specific PCR primers. Primers for the RNFT2 were as follows: forward 5'GAAAGGACTCCCCTTCATCC-3' and reverse 5'-CCAGCA CTGACCTCTTCTCC-3'. Real-time detection of SYBR ${ }^{\circledR}$ Green fluorescence intensity was performed using the ABI StepOnePlus Real-Time PCR System (Applied Biosystems, Foster City, CA, USA). The glyceraldehyde-3-phosphate dehydrogenase (GAPDH) expression was used as an internal standard. The qRT-PCR were performed in triplicate for each sample. Expression levels are presented as the value for RNFT2 divided by that of GAPDH. The expression levels of 84 additional genes were analyzed using the Human Epithelial to Mesenchymal Transition (EMT) RT Profiler 

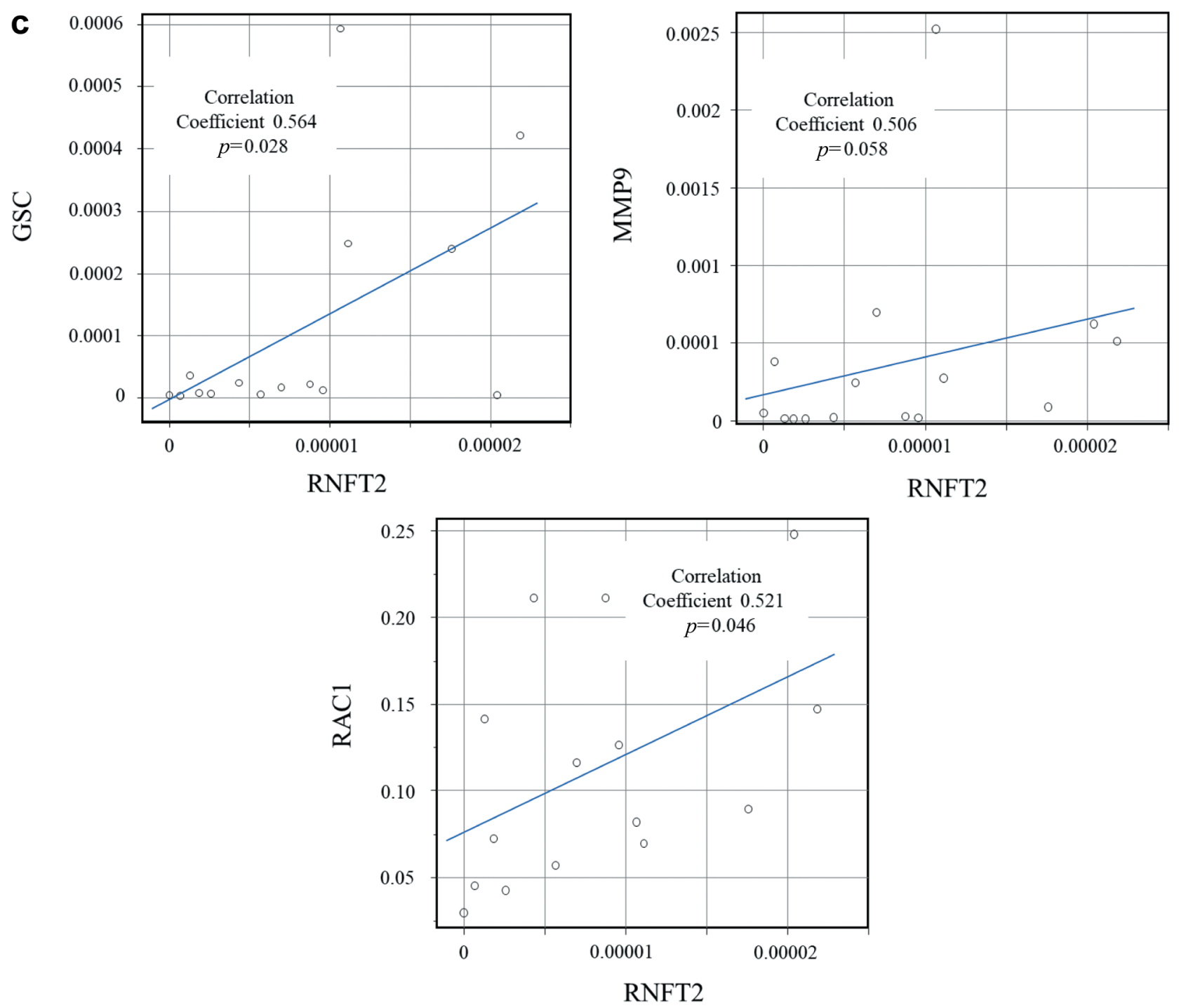

Figure 1. Analysis of RNFT2 expression in 14 gastric cancer cell lines and EMT-related genes. (a) Quantitative RT-PCR analysis of RNFT2 mRNA expression in gastric cancer cell lines and a control cell line. (b) PCR array analysis of RNFT2 and EMT-related genes. (c) Correlation analysis between RNFT2 and GSC, MMP9, and RAC1.

PCR Array (Qiagen, Hilden, Germany) and correlated to the expression of RNFT2 to identify genes associated with RNFT2 in gastric cancer cell lines.

Collection of clinical samples. Between 2001 and 2017, primary gastric cancer tissues and corresponding normal adjacent tissues were collected from 230 patients who underwent radical gastrectomy for gastric cancer without neoadjuvant therapy at the Department of Gastroenterological Surgery, Nagoya University Hospital. All patients were classified histologically in accordance with the $8^{\text {th }}$ edition of the Union for International Cancer Control (UICC) classification (7). Tissue samples were immediately frozen in liquid nitrogen and stored at $-80^{\circ} \mathrm{C}$. Tumor samples without necrotic areas were extracted by gross observation. Corresponding normal adjacent gastric mucosa samples $>5 \mathrm{~cm}$ from the edge of the tumors were obtained from the same patient. Patients were pathologically diagnosed with stages I-III gastric cancer, and relevant clinicopathological parameters were acquired from patient medical records. Since 2006, adjuvant chemotherapy using S-1 (an oral fluorinated pyrimidine) was administered to all UICC stage II-III patients with gastric cancer, unless contraindicated by the patient's condition (8).

Evaluation of the clinical significance of RNFT2 expression. RNFT2 mRNA levels were measured in 230 matched pairs of resected gastric tissues. For external validation of the data, a freely available integrated dataset comprising 1065 patients from three major cancer research centres (Berlin, Bethesda and Melbourne datasets) was accessed at http://kmplot.com/analysis/ (9). 


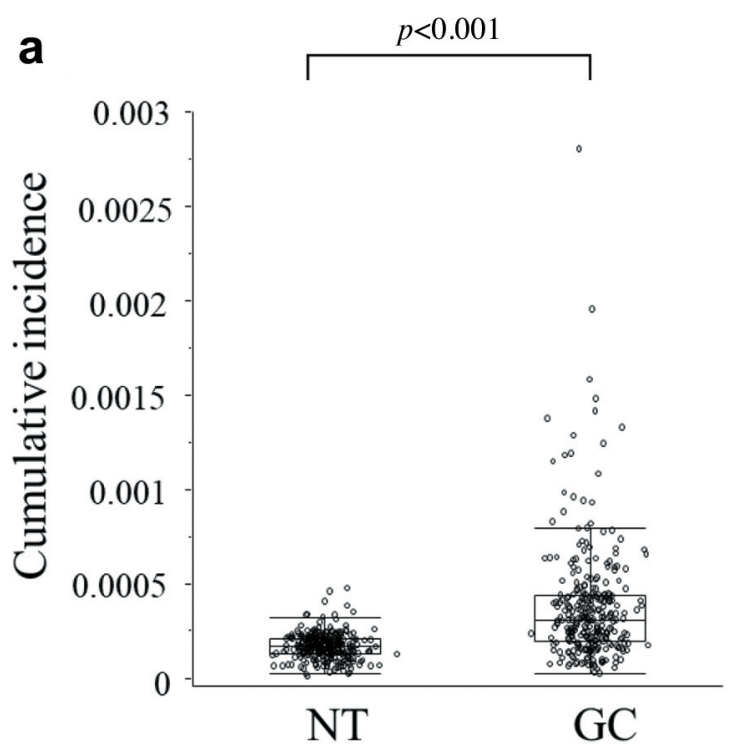

b

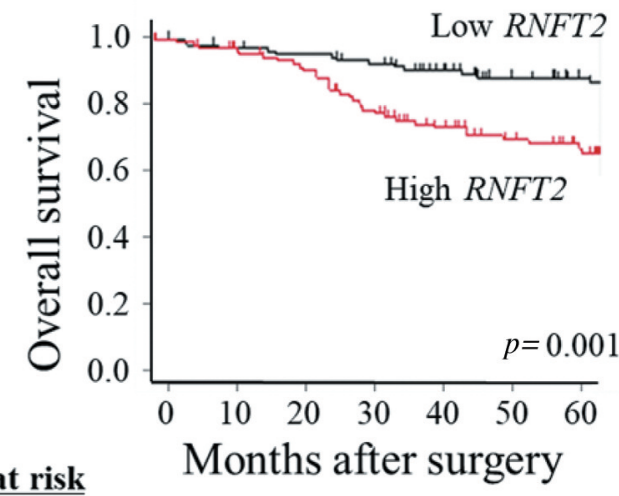

No. at risk

$\begin{array}{llllllll}\text { Low RNFT2 } & 115 & 111 & 108 & 103 & 91 & 79 & 70\end{array}$

High RNFT2 $115 \quad 110 \quad 99 \quad 84 \quad 69 \quad 59 \quad 42$

\section{Extra-validation dataset}

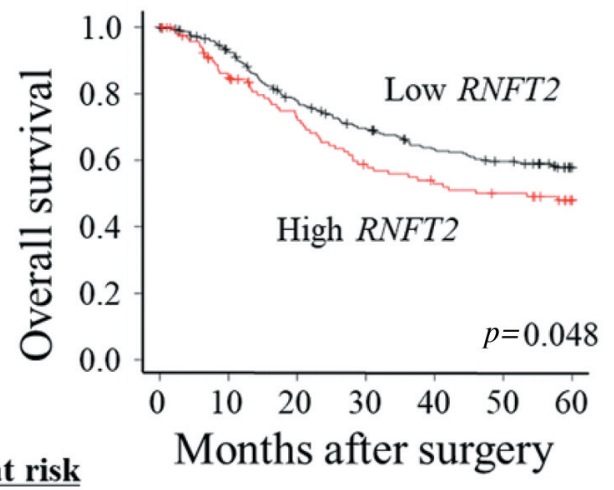

No. at risk

Low RNFT2 323286236207183170148

High RNFT2 $122 \quad 96 \quad 77 \quad 61 \quad 54 \quad 50 \quad 40$

Figure 2. RNFT2 mRNA expression in gastric cancer and normal tissues and its correlation with prognosis. (a) Comparison of RNFT2 mRNA expression in gastric cancer (GC) tissues and normal adjacent tissues (NT). (b) Overall survival time of 230 patients with stage I-III gastric cancer and an extra-validation dataset, according to high and low RNFT2 expression.

Statistical analysis. Relative levels of mRNA expression (RNFT2/ $G A P D H)$ between gastric cancer and adjacent normal tissues were examined using the Mann-Whitney $U$-test. The $\chi^{2}$ test was used to analyze the significance of the association between RNFT2 expression and clinicopathological parameters. The significance of the correlation between RNFT2 and EMT-related genes was assessed using Spearman's rank correlation coefficient.

Overall survival and disease-free survival rates were calculated using the Kaplan-Meier method, and the difference in survival curves was analyzed using the log-rank test. Multivariate regression analysis was performed to detect prognostic factors using the Cox proportional hazards model and variables with $p<0.05$ were entered into the final model. All statistical analyses were performed using JMP 15 software (SAS Institute Inc., Cary, NC, USA). A value of $p<0.05$ was considered statistically significant.

\section{Results}

Identification of RNFT2 as a candidate gastric cancer-related gene. We conducted a comprehensive expression analysis of primary cancerous tissues obtained from patients with concurrent hepatic metastasis. We compared the mRNA expression levels in normal tissues, cancerous tissues, and 
Table I. RNFT2 expression and clinical characteristics of 230 gastric cancer patients.

\begin{tabular}{|c|c|c|c|}
\hline Variables & $\begin{array}{l}\text { Low } R N F T 2 \\
\quad(\mathrm{n}=115)\end{array}$ & $\begin{array}{l}\text { High } R N F T 2 \\
\quad(\mathrm{n}=115)\end{array}$ & $p$-Value \\
\hline \multicolumn{4}{|l|}{ Age } \\
\hline$<70$ year & 75 & 63 & \multirow[t]{2}{*}{0.106} \\
\hline$\geq 70$ year & 40 & 52 & \\
\hline \multicolumn{4}{|l|}{ Gender } \\
\hline Male & 77 & 88 & \multirow[t]{2}{*}{0.107} \\
\hline Female & 38 & 27 & \\
\hline \multicolumn{4}{|l|}{ CEA (ng/ml) } \\
\hline$\leq 5$ & 101 & 94 & \multirow[t]{2}{*}{0.196} \\
\hline$>5$ & 14 & 21 & \\
\hline \multicolumn{4}{|l|}{ CA19-9 (IU/ml) } \\
\hline$\leq 37$ & 95 & 96 & \multirow[t]{2}{*}{0.861} \\
\hline$>37$ & 20 & 19 & \\
\hline \multicolumn{4}{|l|}{ Tumor location } \\
\hline Entire & 4 & 4 & \multirow[t]{4}{*}{0.227} \\
\hline Upper third & 24 & 37 & \\
\hline Middle third & 41 & 39 & \\
\hline Lower third & 46 & 35 & \\
\hline \multicolumn{4}{|l|}{ Tumor size (mm) } \\
\hline$<50$ & 60 & 64 & \multirow[t]{2}{*}{0.597} \\
\hline$\geq 50$ & 55 & 51 & \\
\hline \multicolumn{4}{|l|}{ Macroscopic type } \\
\hline Borrmann type $4 / 5$ & 11 & 11 & \multirow[t]{2}{*}{1.000} \\
\hline Others & 104 & 104 & \\
\hline \multicolumn{4}{|l|}{ Multifocal lesions } \\
\hline Absent & 104 & 105 & \multirow[t]{2}{*}{0.819} \\
\hline Present & 11 & 10 & \\
\hline \multicolumn{4}{|l|}{ Tumor depth (UICC) } \\
\hline pT1-3 & 76 & 71 & \multirow[t]{2}{*}{0.492} \\
\hline pT4 & 39 & 44 & \\
\hline \multicolumn{4}{|l|}{ Differentiation } \\
\hline Differentiated & 50 & 49 & \multirow[t]{2}{*}{0.894} \\
\hline Undifferentiated & 65 & 66 & \\
\hline \multicolumn{4}{|c|}{ Lymphatic involvement } \\
\hline Absent & 21 & 17 & \multirow[t]{2}{*}{0.477} \\
\hline Present & 94 & 98 & \\
\hline \multicolumn{4}{|l|}{ Vascular invasion } \\
\hline Absent & 51 & 37 & 0.057 \\
\hline Present & 64 & 78 & \\
\hline Infiltrative growth ty & & & \\
\hline Invasive growth & 37 & 34 & 0.669 \\
\hline Expansive growth & 78 & 81 & \\
\hline Lymph node metasta & & & \\
\hline Absent & 53 & 34 & 0.010 \\
\hline Present & 62 & 81 & \\
\hline UICC stage & & & \\
\hline I & 27 & 23 & 0.346 \\
\hline II & 39 & 32 & \\
\hline III & 49 & 60 & \\
\hline
\end{tabular}

CEA: Carcinoembryonic antigen; CA19-9: carbohydrate antigen 19-9; UICC: Union for International Cancer Control.

hepatic metastases, and identified genes that were overexpressed in both primary and metastatic cancerous tissues compared with normal tissues. Among them, we selected $R N F T 2$ for the following reasons: no previous studies on RNFT2 mRNA expression in gastric cancer have been reported, primers suitable for qPCR assay can be designed, and expression analysis was feasible in a pilot study using a small number of clinical specimens. A transcriptome analysis revealed that RNFT2 expression was upregulated in primary gastric cancer tissues $\left(\log _{2} 1.034\right)$ and metastases $\left(\log _{2} 3.187\right)$ compared with non-cancerous areas. RNFT2 has been reported to mediate protein interactions and participate in the ubiquitination of target proteins, however, a thorough understanding of its precise function remains to be established. Therefore, we focused on RNFT2 which may be associated with the malignancy of gastric cancer.

Analysis of RNFT2 mRNA expression in gastric cancer cell lines. To characterize RNFT2 in gastric cancer, we evaluated $R N F T 2$ mRNA expression in 14 gastric cancer cell lines compared with control epithelial cells. RNFT2 expression was higher in 10 gastric cell lines (N87, MKN1, IM95, MKN7, MKN74, NUGC3, GCIY, MKN45, KATO-III and OCUM1) compared with FHs74 control cells (Figure 1a). RNFT2 mRNA levels were similar between differentiated and undifferentiated carcinomas.

A PCR array analysis of 84 EMT-related genes identified three EMT-related genes: goosecoid homeobox (GSC), matrix metalloproteinase 9 (MMP9) and rac family small GTPase1 (RAC1) whose expression correlated with RNFT2 expression (Spearman coefficient $\geq 0.5$ ) (Figure $1 \mathrm{~b}$ and $\mathrm{c}$ ).

Expression levels of RNFT2 mRNA in surgically resected gastric tissues. We examined the expression of RNFT2 mRNA in cancerous and non-cancerous tissues from 230 patients who underwent radical gastrectomy. The patient population included 165 men and 65 women aged 26 to 96 years (66.2 \pm 10.8 years, mean \pm standard deviation). Pathologically, 99 and 131 patients were diagnosed with differentiated and undifferentiated gastric cancer, respectively. According to the UICC staging system (eighth edition), 50, 71 and 109 patients exhibited the characteristics of pathological stages I, II and III, respectively. The expression of RNFT2 mRNA was significantly higher in cancerous tissues compared with that of non-cancerous adjacent tissues $(p<0.001$; Figure $2 \mathrm{a})$.

Prognostic implications of RNFT2 mRNA expression levels. We categorized patients into high (above the median RNFT2 mRNA expression) and low RNFT2 expression groups. The high RNFT2 expression group exhibited a significant correlation with positive lymph node metastasis, but there was no difference in age, sex, degree of differentiation, or UICC stage (Table I). The overall survival rate was significantly shorter in the high RNFT2 expression group compared with the low RNFT2 expression group, and extra-validation data showed a similarly poor prognosis and reproducibility in the 
Table II. Prognostic factors for disease-free survival in 230 gastric cancer patients.

\begin{tabular}{|c|c|c|c|c|c|c|c|}
\hline \multirow[t]{2}{*}{ Variables } & \multirow[t]{2}{*}{$\mathrm{n}$} & \multicolumn{3}{|c|}{ Univariate } & \multicolumn{3}{|c|}{ Multivariable } \\
\hline & & Hazard ratio & $95 \% \mathrm{CI}$ & $p$-Value & Hazard ratio & $95 \% \mathrm{CI}$ & $p$-Value \\
\hline Age $(\geq 70)$ & 92 & 0.82 & $0.49-1.39$ & 0.420 & & & \\
\hline Gender (female) & 65 & 0.95 & $0.57-1.58$ & 0.834 & & & \\
\hline CEA $(>5 \mathrm{ng} / \mathrm{ml})$ & 35 & 1.27 & $0.68-2.36$ & 0.453 & & & \\
\hline CA 19-9 (>37 IU/ml) & 39 & 2.35 & $1.37-4.03$ & 0.002 & 1.70 & $0.98-2.98$ & 0.060 \\
\hline Tumor location (lower third) & 81 & 0.76 & $0.46-1.27$ & 0.297 & & & \\
\hline Tumor size $(\geq 50 \mathrm{~mm})$ & 106 & 1.95 & $1.21-3.15$ & 0.006 & 1.41 & $0.87-2.30$ & 0.168 \\
\hline Macroscopic type (Borrmann type 4/5) & 22 & 2.32 & $1.27-4.24$ & 0.007 & 1.32 & $0.679-2.59$ & 0.410 \\
\hline Multifocal lesions & 21 & 0.90 & $0.39-2.09$ & 0.816 & & & \\
\hline Tumor depth (pT4, UICC) & 83 & 2.55 & $1.59-4.08$ & $<0.001$ & 1.50 & $0.88-2.55$ & 0.139 \\
\hline Tumor differentiation (undifferentiated) & 131 & 1.59 & $0.97-2.60$ & 0.066 & & & \\
\hline Lymphatic involvement & 192 & 4.12 & $1.50-11.3$ & 0.006 & 0.95 & $0.30-3.07$ & 0.936 \\
\hline Vascular invasion & 142 & 2.66 & $1.52-4.65$ & $<0.001$ & 1.34 & $0.72-2.49$ & 0.348 \\
\hline Invasive growth & 71 & 1.66 & $1.03-2.69$ & 0.038 & 1.22 & $0.69-2.14$ & 0.501 \\
\hline Lymph node metastasis & 143 & 7.97 & $3.63-17.5$ & $<0.001$ & 4.82 & $1.96-11.8$ & $<0.001$ \\
\hline High $R N F T 2$ & 115 & 2.14 & $1.31-3.50$ & 0.002 & 1.85 & $1.12-3.06$ & 0.016 \\
\hline
\end{tabular}

CI: Confidence interval; CEA: carcinoembryonic antigen; CA19-9: carbohydrate antigen 19-9; UICC: Union for International Cancer Control.

high RNFT2 expression group (5-year survival rates, $67 \%$ and $87 \%$, respectively, $p<0.001$; Figure $2 \mathrm{~b}$ ).

To identify prognostic factors, we performed a univariate analysis for disease-free survival. Carbohydrate antigen (CA) 19$9>37 \mathrm{IU} / \mathrm{ml}$, tumor size ( $\geq 50 \mathrm{~mm}$ ), macroscopic type (Borrman type 4/5), pT4, lymphatic involvement, vascular invasion, invasive growth, lymph node metastasis, and high RNFT2 mRNA expression were detected as significant poor prognostic factors. Multivariate analysis of disease-free survival revealed that high RNFT2 expression and lymph node metastasis were significantly independent poor prognostic factors (Table II).

Disease-free survival was significantly shorter in the high RNFT2 expression group compared with the low RNFT2 expression group (5-year, disease-free survival rates, $61 \%$ and $80 \%$, respectively, $p=0.002$; Figure $3 \mathrm{a}$ ). The frequency of peritoneal recurrence was significantly higher in the high $R N F T 2$ expression group compared with the low RNFT2 expression group (Figure $3 \mathrm{~b}$ ). The cumulative incidence of peritoneal recurrence was significantly higher in the high RNFT2 group compared with the low RNFT2 expression group (Figure 3c).

\section{Discussion}

In the present study, we identified a novel gene that may serve as a biomarker for metastasis and recurrence in gastric cancer. We performed a comprehensive expression analysis of gastric tissues from patients with hepatic metastasis and identified the RNFT2 gene as highly expressed in cancerous and metastasis tissues compared with non-cancerous tissues. RNFT2 expression levels were positively correlated with several EMT-related molecules. The high RNFT2 mRNA expression group exhibited a high recurrence rate after curative gastrectomy, especially peritoneal recurrence, and shorter overall survival. This result was also observed in the extra-validation dataset.

Human RNFT2, located on chromosome 12q24.22, encodes a 48,965-Da protein consisting of 444 amino acids. RNFT2 is a member of the ring finger family and has been implicated in proteolysis in the cytosol and nucleus. It is highly expressed in the brain and testis and ubiquitously expressed in multiple organs including the gastrointestinal tract, liver, adrenal gland, and lung. RNFT2 has been reported to decrease lung inflammation and damage by ubiquitinating and degrading IL3Ra, the receptor for the IL-3 inflammatory cytokine (10). There have been no reports of an association between malignancy and RNFT2 and only a few reports suggest that RNFT1 is involved in the suppression of metastasis in breast cancer (11). To our knowledge, this is the first study to evaluate the association between RNFT2 and gastric cancer.

We conducted a PCR array analysis to identify genes that are associated with RNFT2 expression and metastasis in gastric cancer. RNFT2 was positively correlated with the expression of the EMT-related molecules GSC, MMP9, and RAC1. EMT is an important process that regulates the migration and invasion of cancer cells and is required for the development of metastatic lesions. EMT involves a complex group of molecules consisting primarily of transcription factors (12). MMP9 changes epithelial cells into mesenchymal cells by degrading the extracellular matrix and basement membrane and causing a loss of epithelia integrity, which results in a loss of adhesion to surrounding cells. One of the features of EMT is decreased expression of Ecadherin. MMP9 degrades epithelial E-cadherin, which results 

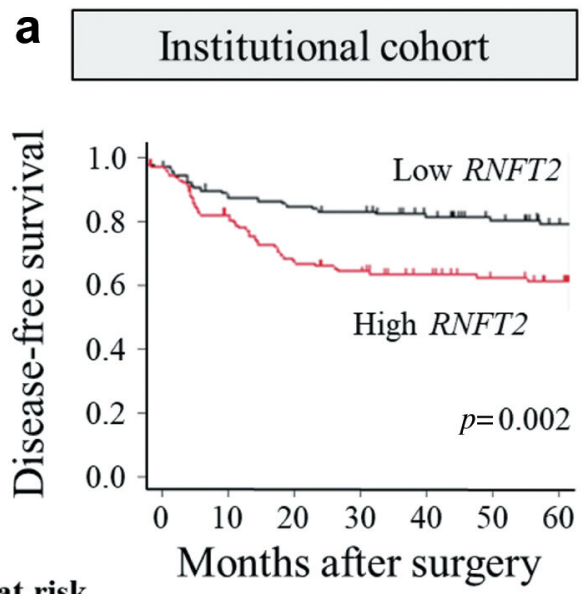

No. at risk

$\begin{array}{llllllll}\text { Low RNFT2 } & 115 & 104 & 98 & 95 & 86 & 76 & 67\end{array}$

High RNFT2 $115 \quad 94 \quad 76 \quad 69 \quad 61 \quad 54 \quad 42$
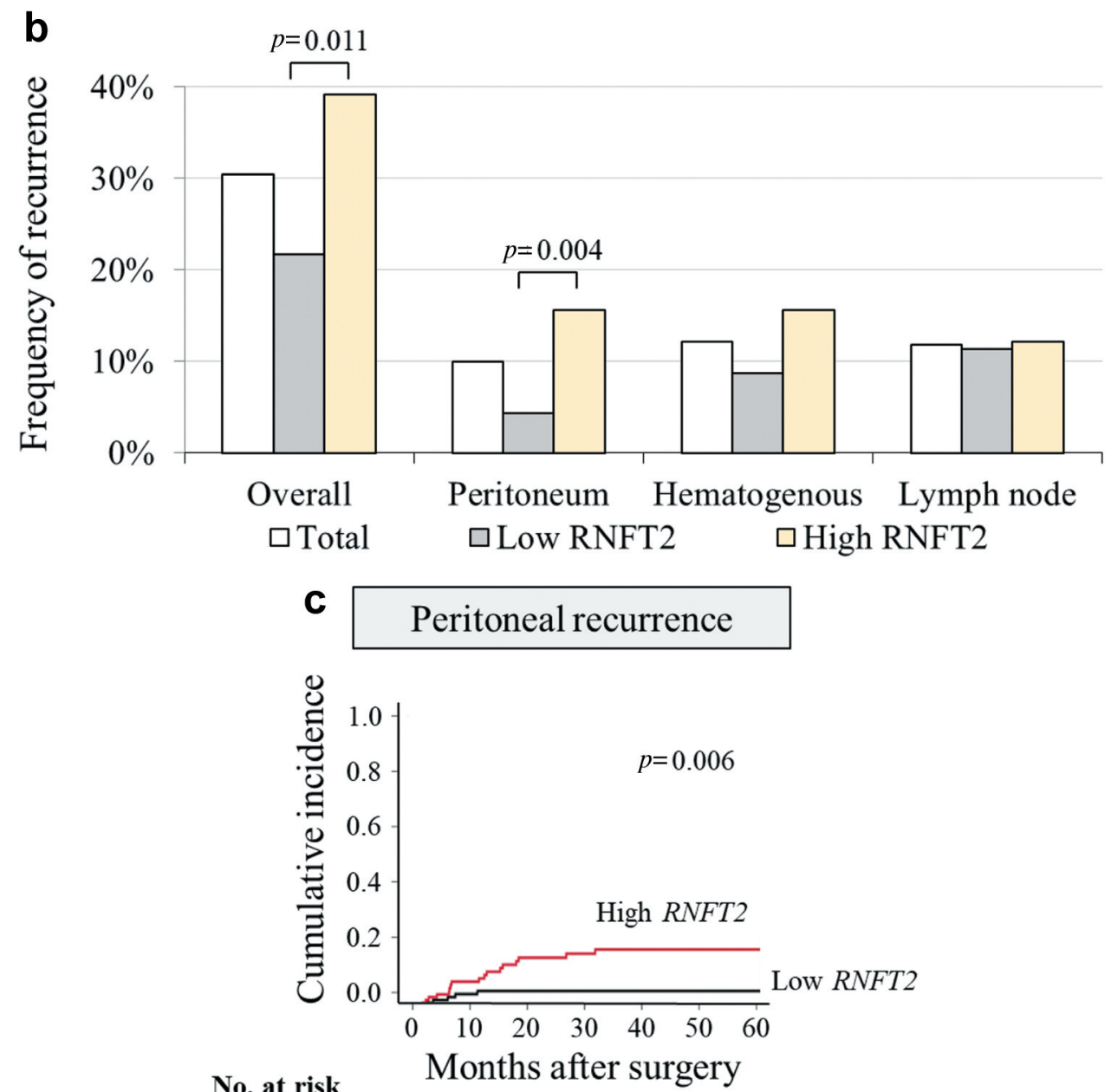

No. at risk

Months after surgery

$\begin{array}{llllllll}\text { Low } R N F T 2 & 115 & 104 & 98 & 95 & 86 & 76 & 67\end{array}$

High RNFT2 $115 \quad 94 \quad 76 \quad 69 \quad 61 \quad 54 \quad 42$

Figure 3. Clinical significance of RNFT2 mRNA expression. (a) Disease-free survival time in 230 patients with stage I-III gastric cancer according to high and low RNFT2 expression levels. (b) Frequency of initial recurrence sites after curative gastrectomy in patients according to RNFT2 mRNA expression. (c) Cumulative incidence of peritoneal recurrence. 
in the dissociation of $\beta$-catenin from the adherens junction and its transfer to the nucleus. $\beta$-catenin accumulates in the nucleus and functions as a transcription factor to activate target genes of the Wnt signalling pathway that promote cell growth and metastasis (13). In breast cancer, MMP9 has been reported to be involved in angiogenesis and cancer cell migration (14). RAC1 is a member of the Rho family of G proteins, which are involved in cell proliferation, cytoskeleton formation, and tumor growth by activating the PI3k/Akt signalling pathway (15). Over-expression of GSC induces EMT and promotes tumor migration and invasion. In HCC, over-expression of GSC has been shown to be associated with distant metastasis and shorter survival (16). In breast cancer, GSC expression has been reported to be associated with metastasis (17). These associations suggest a molecular mechanism for RNFT2 in metastasis and the recurrence of gastric cancer.

Currently in clinical practice, classic serum tumor markers (e.g., carcinoembryonic antigen (CEA) and CA19-9) are used as biomarkers to determine the malignancy of gastric cancer $(18,19)$. However, in the present study, we did not observe an association between preoperative serum CEA levels and overall survival. Elevated CA19-9 levels were significantly associated with disease-free survival in a univariate analysis, but were not associated with disease-free survival in a multivariate analysis. We analyzed patients with stage I-III gastric cancer after curative resection. We considered the patients with stage IV gastric cancer to be unsuitable for the analysis of the correlation between RNFT2 mRNA expression and prognosis because stage IV encompasses a wide range of cases, from only microscopic free cancer cells in the abdominal cavity (CY1P0H0M0) to systemic multiple metastases. Increased RNFT2 expression was an independent poor prognostic factor and was considered superior to classic serum tumor markers as a prognostic biomarker after curative resection.

High levels of RNFT2 expression in primary cancerous tissue predicted a high risk of recurrence, in particular, peritoneal recurrence. Peritoneal recurrence is a problem because of the difficulty of early detection by computed tomography (20). Nakanishi et al. have analyzed mRNAs in peritoneal lavage fluid samples and reported that synaptotagmin XIII (SYT13) and CEA levels may be predictive factors of peritoneal recurrence after curative resection (21). The combination of these molecular markers resulted in a more accurate risk assessment of patients with high RNFT2 expression and may lead to improved precision medicine $(21,22)$.

Considering our results, in cases of high RNFT2 expression in preoperative biopsy specimens, staging laparoscopy may be recommended to search for gross peritoneal dissemination and peritoneal lavage cytology to identify microscopic free cancer cells in the abdominal cavity (23). Large clinical trials have shown that postoperative adjuvant chemotherapy with an S-1 based regimen (S-1 monotherapy, docetaxel plus S-1) reduces postoperative peritoneal recurrence $(24,25)$. Because of the high risk for peritoneal recurrence in patients with high $R N F T 2$ expression, S-1-based chemotherapy may be recommended. During postoperative surveillance, increased attention should be given to abdominal symptoms and periodic abdominal ultrasonography should be performed to search for ascites to detect peritoneal recurrence at an early stage. If increased ascites is observed, a staging laparoscopy may be recommended to make a definitive diagnosis.

Our study has several limitations. First, expression analyses were performed retrospectively at a single institution. Second, the study subjects were acquired over a long time period making it impossible to eliminate potential bias. Third, although we adopted a median cut-off value for RNFT2 mRNA expression, our results may improve if a cut-off value with higher sensitivity and specificity is identified. Last, functional analyses are necessary to clarify the underlying mechanism of the effects of RNFT2 on the pathology of gastric cancer.

\section{Conclusion}

We demonstrated that high RNFT2 mRNA expression in gastric cancer tissue is an independent poor prognostic factor following curative resection. RNFT2 may represent a useful biomarker for predicting peritoneal recurrence and prognosis.

\section{Conflicts of Interest}

The Authors have no conflicts of interest to declare regarding this study.

\section{Authors' Contributions}

MS and MK conceived the study concept and design, analyzed data and wrote the manuscript. MK, DS and YK contributed to data acquisition and interpretation. CT, IY, NH, MH, GN and YK revised the draft. All Authors have read and approved the final version of the manuscript.

\section{Acknowledgements}

The Authors thank Edanz Group (https://en-author-services. edanzgroup.com/ac) for editing a draft of this manuscript.

\section{References}

1 Van Cutsem E, Sagaert X, Topal B, Haustermans K and Prenen H: Gastric cancer. Lancet 388: 2654-2664, 2016. PMID: 27156933. DOI: 10.1016/S0140-6736(16)30354-3

2 Kanda M, Shimizu D, Tanaka H, Tanaka C, Kobayashi D, Hayashi M, Iwata N, Niwa Y, Yamada S, Fujii T, Sugimoto H, Murotani K, Fujiwara M and Kodera Y: Significance of SYT8 for the detection, prediction, and treatment of peritoneal metastasis from gastric cancer. Ann Surg 267: 495-503, 2018. PMID: 28026832. DOI: 10.1097/SLA.0000000000002096

3 Kanda M, Tanaka H, Shimizu D, Miwa T, Umeda S, Tanaka C, Kobayashi D, Hattori N, Suenaga M, Hayashi M, Iwata N, Yamada 
S, Fujiwara M and Kodera Y: SYT7 acts as a driver of hepatic metastasis formation of gastric cancer cells. Oncogene 37: 53555366, 2018. PMID: 29858600. DOI: 10.1038/s41388-018-0335-8

4 Wadhwa R, Song S, Lee JS, Yao Y, Wei Q and Ajani JA: Gastric cancer - Molecular and clinical dimensions. Nat Rev Clin Oncol 10: 643-655, 2013. PMID: 24061039. DOI: 10.1038/nrclinonc. 2013.170

5 Kanda M, Suh YS, Park DJ, Tanaka C, Ahn SH, Kong SH, Lee HJ, Kobayashi D, Fujiwara M, Shimada H, Cho BL, Murotani K, Kim HH, Yang HK and Kodera Y: Serum levels of ANOS1 serve as a diagnostic biomarker of gastric cancer: a prospective multicenter observational study. Gastric Cancer 23: 203-211, 2020. PMID: 31377880. DOI: 10.1007/s10120-019-00995-z

6 Kanda M, Shimizu D, Tanaka H, Tanaka C, Kobayashi D, Hayashi M, Takami H, Niwa Y, Yamada S, Fujii T, Sugimoto H and Kodera Y: Synaptotagmin XIII expression and peritoneal metastasis in gastric cancer. Br J Surg 105: 1349-1358, 2018. PMID: 29741294. DOI: 10.1002/bjs.10876

7 Liu JY, Peng CW, Yang XJ, Huang CQ and Li Y: The prognosis role of AJCC/UICC 8th edition staging system in gastric cancer, a retrospective analysis. Am J Transl Res 10: 292-303, 2018. PMID: 29423014.

8 Kanda M, Murotani K, Kobayashi D, Tanaka C, Yamada S, Fujii T, Nakayama G, Sugimoto H, Koike M, Fujiwara M and Kodera Y: Postoperative adjuvant chemotherapy with S-1 alters recurrence patterns and prognostic factors among patients with stage II/III gastric cancer: A propensity score matching analysis. Surg (United States) 158: 1573-1580, 2015. PMID: 26120068. DOI: $10.1016 /$ j.surg.2015.05.017

9 Szász AM, Lánczky A, Nagy Á, Förster S, Hark K, Green JE, Boussioutas A, Busuttil R, Szabó A and Gyorffy B: Crossvalidation of survival associated biomarkers in gastric cancer using transcriptomic data of 1,065 patients. Oncotarget 7: 49322-49333, 2016. PMID: 27384994. DOI: 10.18632/oncotarget.10337

10 Tong Y, Lear TB, Evankovich J, Chen Y, Londino JD, Myerburg MM, Zhang Y, Popescu ID, McDyer JF, McVerry BJ, Lockwood KC, Jurczak MJ, Liu Y and Chen BB: The RNFT2/IL-3R $\alpha$ axis regulates IL-3 signaling and innate immunity. JCI Insight 5(3): e133652, 2020. PMID: 31990690. DOI: 10.1172/jci.insight.133652

11 Tan P, Ye Y, He L, Xie J, Jing J, Ma G, Pan H, Han L, Han W and Zhou Y: TRIM59 promotes breast cancer motility by suppressing p62-selective autophagic degradation of PDCD10. PLoS Biol 16(11): e3000051, 2018. PMID: 30408026. DOI: 10.1371/journal.pbio.3000051

12 Lamouille S, Xu J and Derynck R: Molecular mechanisms of epithelial-mesenchymal transition. Nat Rev Mol Cell Biol 15: 178-196, 2014. PMID: 24556840. DOI: $10.1038 / \mathrm{nrm} 3758$

13 Chen SW, Zhang Q, Xu ZF, Wang HP, Shi Y, Xu F, Zhang WJ, Wang P and Li Y: HOXC6 promotes gastric cancer cell invasion by upregulating the expression of MMP9. Mol Med Rep 14: 32613268, 2016. PMID: 27573865. DOI: 10.3892/mmr.2016.5640

14 Reggiani F, Labanca V, Mancuso P, Rabascio C, Talarico G, Orecchioni S, Manconi A and Bertolini F: Adipose progenitor cell secretion of GM-CSF and MMP9 promotes a stromal and immunological microenvironment that supports breast cancer progression. Cancer Res 77: 5169-5182, 2017. PMID: 28754674. DOI: 10.1158/0008-5472.CAN-17-0914

15 Yoon C, Cho SJ, Chang KK, Park DJ, Ryeom SW and Yoon SS: Role of Rac1 pathway in epithelial-to-mesenchymal transition and cancer stem-like cell phenotypes in gastric adenocarcinoma.
Mol Cancer Res 15: 1106-1116, 2017. PMID: 28461325. DOI: 10.1158/1541-7786.MCR-17-0053

16 Xue TC, Ge NL, Zhang L, Cui JF, Chen RX, You Y, Ye SL and Ren ZG: Goosecoid promotes the metastasis of hepatocellular carcinoma by modulating the epithelial-mesenchymal transition. PLoS One 9: 1-10, 2014. PMID: 25343336. DOI: 10.1371/journal.pone.0109695

17 Taube JH, Herschkowitz JI, Komurov K, Zhou AY, Gupta S, Yang J, Hartwell K, Onder TT, Gupta PB, Evans KW, Hollier BG, Ram PT, Lander ES, Rosen JM, Weinberg RA and Mani SA: Core epithelial-to-mesenchymal transition interactome gene-expression signature is associated with claudin-low and metaplastic breast cancer subtypes. Proc Natl Acad Sci USA 107: 15449-15454, 2010. PMID: 20713713. DOI: 10.1073/pnas.1004900107

18 Kanda M, Murotani K, Tanaka H, Miwa T, Umeda S, Tanaka C, Kobayashi D, Hayashi M, Hattori N, Suenaga M, Yamada S, Nakayama G, Fujiwara M and Kodera Y: Integrated multigene expression panel to prognosticate patients with gastric cancer. Oncotarget 9: 18775-18785, 2018. PMID: 29721160. DOI: 10.18632/oncotarget.24661

19 Kanda M and Kodera Y: Recent advances in the molecular diagnostics of gastric cancer. World J Gastroenterol 21: 98389852, 2015. PMID: 26379391. DOI: 10.3748/wjg.v21.i34.9838

20 Wang $\mathrm{Z}$ and Chen JQ: Imaging in assessing hepatic and peritoneal metastases of gastric cancer: A systematic review. BMC Gastroenterol 11: 19, 2011. PMID: 21385469. DOI: 10.1186/1471230X-11-19

21 Kanda M, Kasahara Y, Shimizu D, Miwa T, Umeda S, Sawaki K, Nakamura S, Kodera Y and Obika S: Amido-bridged nucleic acidmodified antisense oligonucleotides targeting SYT13 to treat peritoneal metastasis of gastric cancer. Mol Ther - Nucleic Acids 22: 791-802, 2020. PMID: 33230476. DOI: 10.1016/j.omtn.2020.10.001

22 Kanda M, Shimizu D, Sawaki K, Nakamura S, Umeda S, Miwa T, Tanaka H, Tanaka C, Hayashi M, Iguchi Y, Yamada S, Katsuno M and Kodera Y: Therapeutic monoclonal antibody targeting of neuronal pentraxin receptor to control metastasis in gastric cancer. Mol Cancer 19: 1-14, 2020. PMID: 32847597. DOI: $10.1186 / \mathrm{s} 12943-020-01251-0$

23 Leake PA, Cardoso R, Seevaratnam R, Lourenco L, Helyer L, Mahar A, Law C and Coburn NG: A systematic review of the accuracy and indications for diagnostic laparoscopy prior to curative-intent resection of gastric cancer. Gastric Cancer 15: 3847, 2012. PMID: 21667136. DOI: 10.1007/s10120-011-0047-z

24 Sasako M, Sakuramoto S, Katai H, Kinoshita T, Furukawa H, Yamaguchi T, Nashimoto A, Fujii M, Nakajima T and Ohashi Y: Five-year outcomes of a randomized phase III trial comparing adjuvant chemotherapy with S-1 versus surgery alone in stage II or III gastric cancer. J Clin Oncol 29: 4387-4393, 2011. PMID: 22010012. DOI: $10.1200 / J C O .2011 .36 .5908$

25 Yoshida K, Kodera Y, Kochi M, Ichikawa W, Kakeji Y, Sano T, Nagao N, Takahashi M, Takagane A, Watanabe T, Kaji M, Okitsu H, Nomura T, Matsui T, Yoshikawa T, Matsuyama J, Yamada M, Ito S, Takeuchi $M$ and Fujii M: Addition of docetaxel to oral fluoropyrimidine improves efficacy in patients with stage III gastric cancer: Interim analysis of JACCRO GC07, a randomized controlled trial. J Clin Oncol 37: 1296-1304, 2019. PMID: 30925125 . DOI: $10.1200 / \mathrm{JCO} .18 .01138$

Received December 15, 2020

Revised December 30, 2020

Accepted December 31, 2020 